\title{
QUALITY ATTRIBUTES OF CONSUMER-BASED M-COMMERCE SYSTEMS
}

\author{
John Garofalakis ${ }^{1,3}$, Antonia Stefani ${ }^{2}$, Vasilios Stefanis ${ }^{1,3}$ and Michalis Xenos ${ }^{2}$ \\ ${ }^{I}$ Research Academic Computer Technology Institute, 26500, Patras, Greece \\ garofala@cti.gr,stefanis@westgate.gr \\ ${ }^{2}$ School of Sciences \& Technology, Software Quality Research Group, Hellenic Open University \\ 23 Sachtouri Str, Patras, Greece \\ stefani@eap.gr,xenos@eap.gr \\ ${ }^{3}$ University of Patras, Computer Engineering \& Informatics Department, 26500 Patras, Greece \\ garofala@ceid.upatras..gr,stefanis@ceid.upatras.gr
}

Keywords: m-commerce Systems, ISO9126, Quality attributes.

\begin{abstract}
In m-commerce applications, the design process still lacks a systematic quality control procedure. These systems are data-intensive, user-driven, and have increasing needs for accessibility, efficiency, adaptivity, portability and competitiveness. In this paper we study the quality of the software on which retail shopping through the mobile web is based, i.e. the software part of B2C (business-to-customer) m-Commerce system. A consumer's perception quality evaluation was conducted to reveal the quality attributes that offer insights into m-commerce systems based on the external quality characteristics of ISO9126 quality standard.
\end{abstract}

\section{INTRODUCTION}

Mobile-commerce (m-commerce) systems have been developed at a significant rate in recent years. In particular, they offer functions and services in order to fulfil the end-users requirements and to provide services of high quality through a more usable and user friendly environment.

M-commerce can be viewed as a subset of ecommerce (Coursaris, 2002; Kwon, 2004) and refers to transaction with monetary value that is conducted via a mobile network (Clarke, 2001). When users conduct e-commerce such as e-banking or purchase products, they do not need to use a personal computer system. Indeed, they can simply use some mobile handheld devices such as Personal Digital Assistants (PDA) and mobile phones. In the past, these mobile devices or their enabling technologies were regarded as a kind of luxury for individuals. However, this situation has changed. The market for mobile technologies has seen significant growth in the past few years (Ngai, 2007). This is creating a new opportunity for the growth of m-commerce.

Location-based services enable m-commerce to be further leveraged so that the mobility aspect is exploited of rather than repackaging old systems in a new format. M-commerce systems have two major characteristics: mobility and broad reach. Mobility implies portability, e.g., users can conduct business in real time via mobile devices. With m-commerce, people can be reached at any time via a mobile device. In this paper, m-commerce refers to conducting commerce via wireless devices and especially via mobile phones and examines end user quality perspective.

The quality of m-commerce systems is an extremely new and challenging task; especially the quality of mobile commerce systems as it is perceived by the end-user is an open research issue for the software quality community. The end user interacts with mobile system using software through mobile devices and expects a well designed environment where he/she can proceed a commercial transaction.

It is with the above observation that this paper examines the quality attributes of $\mathrm{m}$-commerce systems adopting the ISO9126 software quality standard (ISO, 2001). Adopting and adapting ISO 9126 for specific domains is not new to the standard itself (Losavio, 2004; Cote, 2005). The usual approach is to enhance the hierarchical and (by design) open scheme to include more attributes suitable for the new domain. However, enhancing an ISO standard is far from being an easy process. 
The quality of software concerns end-users and developers as well. The main question posed is "Which are the attributes that an m-commerce system should have and how these attributes formulate end user's perspective about m-commerce systems' quality?" Another research question that arises is that "An m-commerce system can be well designed but it can also be characterized as a system with high quality?" In this quality evaluation approach the paper emphasizes at end-user perceptive using the external quality characteristics of ISO9126 namely Functionality, Usability, Efficiency and Reliability.

The paper is structured as follows; in section 2 the theoretical foundations are presented, while in section $3 \mathrm{~m}$-commerce attributes are discussed. In section 4 the evaluation process is presented, while in section 5 the evaluation results and their quality aspect are further discussed. Finally, in section 6 conclusions and future work are presented.

\section{THEORETICAL BACKGROUND}

The method presented in this paper uses the external quality characteristics of the ISO9126 quality standard in order to model the quality attributes of m-commerce systems. We strongly encourage authors to use this document for the preparation of the camera-ready. Please follow the instructions closely in order to make the volume look as uniform as possible. (Moore and Lopes, 1999).

\subsection{The ISO9126 Quality Framework}

ISO9126 is a quality standard for software product evaluation and provides quality characteristics and guidelines for their use (ISO, 2001). This standard, composed of several parts, aims at defining a quality model for software and a set of guidelines for measuring the characteristics associated with it. This work is based on the ISO9126 quality standard and specifically it relies on the external quality characteristics which are directly related to quality as perceived by the end-users.

ISO9126 may be used as basis for m-commerce quality evaluation but further analysis and mapping of its characteristics is required. The main issue is how m-commerce system's quality can be analyzed using this standard. In this work, we use the following external quality characteristics of ISO 9126: Functionality, Usability, Efficiency and Reliability. Each of the above mentioned characteristics provide the quality framework (actually the baseline) on which an m-commerce system may be built, taking into account the satisfaction of end-users requirements. The external quality characteristics of ISO9126 are defined as follows.

\subsubsection{Functionality}

Functionality refers to a set of functions and specified properties that satisfy stated or implied needs (ISO, 2001). The meaning of Functionality is to provide integrative and interactive functions in order to ensure end-user convenience. Especially for m-commerce systems Functionality refers to the existence of these functions and services that support end user's interaction via the mobile system.

\subsubsection{Usability}

Usability is defined as a set of attributes that bear on the effort needed for the use of a product or service, based on the individual assessment of such use by a stated or implied set of users (ISO, 2001). Usability is an important quality characteristic as all functions of an m-commerce system are usually developed in a way that seeks to facilitate the end-user by simplifying end-user's actions; this fact can however affect negatively the system in certain cases.

\subsubsection{Efficiency}

Efficiency is a complex concept that entails both conceptual challenges as well as implementation difficulties. Efficiency is defined as the capability of the system to provide appropriate performance, relative to the amount of resources used, under stated conditions (ISO, 2001). It refers to a state where system functions are both usable and successful, i.e. they achieve their aim, the reason for their existence. One of the main criteria of efficiency of an m-commerce system is the quality relating to time and resource behaviour.

\subsubsection{Reliability}

Reliability is the quality characteristic that refers to a set of attributes that bear on the capability of software to maintain its performance level under stated conditions for a stated period of time (ISO, 2001). Especially for m-commerce systems reliability refers to systems tolerance on end users actions. 


\section{M-COMMERCE SYSTEM ATTRIBUTES}

Currently, m-commerce is in its early stages of development and little is known about the factors that influence quality's attitudes and their value from the end-users' perceptions. Mobile commerce systems include mobile financial systems, mobile advertising, mobile inventory management, product locating and shopping, wireless reengineering, mobile auction, and wireless data center (Malloy, 2002). These systems aim to provide the appropriate attributes/functions for the end user in order to complete a purchase or to get information using his/her mobile device. The basic advantage of $\mathrm{m}$ commerce systems is that location and time do not constrain people from completing their transactions.

In order to model the interactions among the end user and the m-commerce system we consider three different steps: Presentation, Navigation and Purchasing. Presentation describes how a product or service is presented to the end-user. Navigation describes the various mechanisms provided to the end user for accessing information and services of the m-commerce system. Purchasing refers to the facilities provided for the commercial transaction per se. Applying the above steps to m-commerce requires an adjustment to the attributes that the system presents because of its wireless communication character. In the following paragraphs we present the attributes of mobile systems that constitute the end-user purchasing process. The definition of these attributes is basically based on the literature for mobile web practices and especially on Mobile Web Best Practices 1.0, W3C Proposed Recommendation (W3C, 2006), e-commerce and m-commerce previous experience (Stefani, 2004; Stefani, 2005; Blekas, 2006). In this work m-commerce attributes are categorized in the above categories providing an overview of m-commerce systems' quality from end users' point of view.

The aim of this paper is not to describe all existing $\mathrm{m}$-commerce attributes or fully present their use but rather to offer a quality evaluation of these attributes and to present a quality framework for $\mathrm{m}$ commerce systems.

\subsection{Presentation}

Presentation is supported basically by text and images because mobile devices have limitations such as screen size and resolution, number of supported colors, computation power, memory size, rate of data transfer and energy required for proper functionality. Color usage is also important. Using colors obviously gives a pleasant and friendly interface, but a too colored screen confuses. All the pages of the m-commerce system must have the same colors so the user can feel that he/she is navigating in the same environment. By removing background images, background colors and text colors the readability of the content is increased. The use of images in Internet applications is common. Nevertheless, using images in mobile web applications significantly increases download and response time and thus, usage cost.

Presentation issues are also related to issues such as thematic consistency and the default delivery context which intends to provide an acceptable mobile environment for any end user from different mobile devices. The clarity of the text presented with meaningful, short and simple words and the presentation of the central meaning at the first page of each mobile device contributes attributes that a $\mathrm{m}$-commerce system should provide to the end user for an accessible mobile environment. Additionally, providing a descriptive title for the page allows easy identification of the content; by keeping the title short reduces page weight.

\subsection{Navigation}

The navigability of an m-commerce system is a critical factor for its success. Navigation is an important design element, allowing users to acquire the information they are seeking and making that information easier to find.

Navigation issues support m-commerce systems quality by taking into account the quality of components such as indexes, navigation bars, site maps and quick links. The availability of these components facilitates access to information and services and enables users to locate efficiently the information they need, while avoiding usability bottlenecks. Additionally, navigation concerns the facilities for accessing information and the connectivity of the above systems.

Navigation refers at attributes that support the navigability of m-commerce systems. These refer to navigation bars, which according to W3C Mobile Web Best Practices 1.0, should be placed on the top of the page. Any other secondary navigational element may be placed at the bottom of the page if really needed. It is important that users should be able to see page content once the page has been loaded with the minimum possible scrolling. Mcommerce systems, as e-commerce systems provide 
simple metaphors such as shopping cart where the end-user may add the products that he/she intends to buy. Mobile devices present limitations on text inputting so an m-commerce system should be enabled by attributes such as access keys (keyboard short cuts), by providing defaults at any function that the user should select an action and also by avoiding free text with minimum text inputting. The navigability of the mobile system is also supported from search services which are related with device capabilities and context presentation as well. Search with simple text inputting in an AND/OR operator format enables the user to find the information needed without navigating to several mobile pages. Search attributes can reduce the cost of mobile browsing and prevent navigability difficulties.

Additionally, because of the limitations in display and input mechanisms, the possible absence of a pointing device and other constraints of mobile devices, care should be exercised in defining the structure and the navigation model of a Web site. Especially the use of links should be limited aiming at providing a balance between having a large number of navigation links on a page and the need to navigate multiple links to reach content.

\subsection{Purchasing}

Purchasing refers to all m-commerce systems attributes that strongly support their commercial character. In particular, it refers to attributes that support the interaction with the m-commerce system. These attributes are also related to the navigability of the system but they are categorized differently because of their significant contribution to the purchasing process.

Localization services may enable the presentation of the products and service because the m-commerce system can recommend the best selection based on end user's positioning. Authentication and personalization attributes support an m-commerce system where the end user can provide private information (ie. Credit Card Number). Additionally notification services provide a great advantage to $\mathrm{m}$-commerce systems because they can also be combined with localized information. Alternative payment methods support either a complete transaction via the m-commerce system or otherwise combined with localized information allow mobile users to conclude transactions efficiently (e.g. receive a product at a selling point closest to the user's current location) (Samaras, 2002).

Purchasing process success is also related to the stability of the process via the m-commerce system and issues like error tolerance and error recovery are crucial.

\section{QUALITY EVALUATION METHOD}

Quality evaluation of mobile applications, as long as the end user's requirements are concerned, gives emphasis on the systems' quality and especially on ISO9126 external quality characteristics: Functionality (F), Usability (U), Efficiency (E) and Reliability (R). It is within this framework that the end-users, who are also the customers of a mobile network, will specify the relative significance for each function that the mobile system provides to the user.

End-user is the best judge (when properly questioned) of the degree to which their needs are satisfied, and thus of the quality of the system viewed as a service. For the presented study, three expert quality evaluators were selected in a heuristic evaluation method (Nielsen, 1990). Heuristic evaluation is performed by looking at an interface and trying to come up with an opinion about what is good and bad about the interface. Ideally people would conduct such evaluations according to certain rules, such as those listed in typical guidelines documents. The evaluators for this method are IT experts with experience in quality evaluation and mobile systems as well. The nature of the presented evaluation method demands the use of expert evaluators because of its technical character.

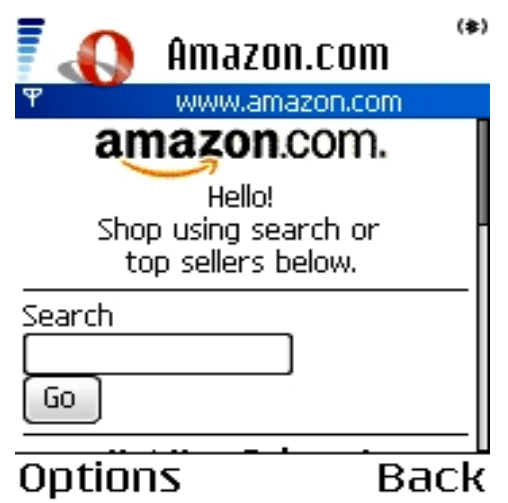

Figure 1: Amazon's m-commerce system from Nokia N70.

Firstly, the evaluators were asked to a complete purchase using a mobile phone and an emulator from their PC. For the evaluation process we have used the Nokia N 70 mobile phone. The N70 has a screen with resolution $176 \times 208$ pixels and supports 
262.144 colors. The phone can also connect to $3 \mathrm{G}$ networks for high rate data transfers using the Opera Mobile 8.51 browser. In order to avoid operability issues for the Nokia N70, help about the functionalities of the device was provided during the evaluation process. Additionally the emulator that has been used was the Openwave Simulator (version 7).

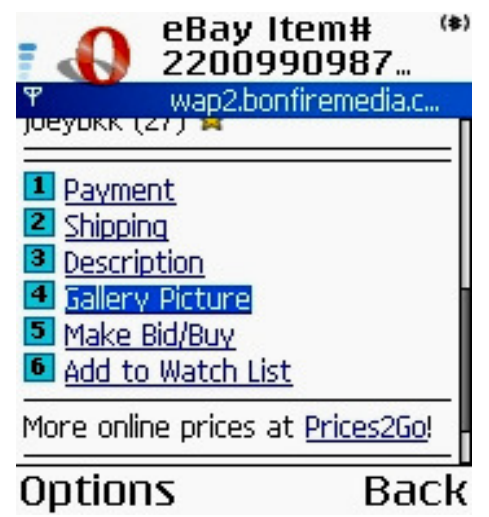

Figure 2: E-bay's m-commerce system from Nokia N70.

The three evaluators used three popular mcommerce systems according to the Mobile Web Google Search (www.google.com/xhtml) in order to have the best $\mathrm{m}$-commerce experience possible. The m-commerce systems that have been selected were Amazon.com, Ebay.com and Movietickets.com. Each evaluator was asked to asses specific mcommerce attributes and to evaluate each one by assigning a value of relevance (rij). Relevance defines the correlation among the m-commerce systems attribute $\mathrm{i}$ (presented in table 1) and software quality characteristic $\mathrm{j}$ ordered as they presented in this work (i.e. $\mathrm{j}=1$ for Functionality, $\mathrm{j}=2$ for Usability, $\mathrm{j}=3$ for Efficiency and $\mathrm{j}=4$ for Reliability) using a five-grade Liker-type scale (1). Each evaluator selected a different value for each quality characteristic from the Liker-type scale assigning scale.

$$
r_{i, j}=\left\{\begin{array}{l}
1, \text { no correlation } \\
2, \text { weak correlation } \\
3, \text { strong correlation } \\
4, \text { very strong correlation } \\
5, \text { critical correlation }
\end{array}\right.
$$

This provides a qualitative representation of $\mathrm{m}$ commerce systems quality and especially gives emphasis on external quality characteristics.

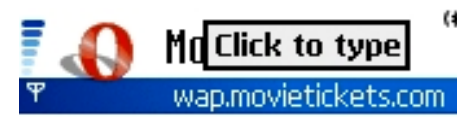

Showtime: $10: 15 \mathrm{pm}$, the evening of Wed, Apr. 4

ADULT @ $\$ 9.75$ USD 1

CHILD/SENIOR @ \$7.00 USD 0

Options Back

Figure 3: Movietickets' m-commerce system from Nokia N70.

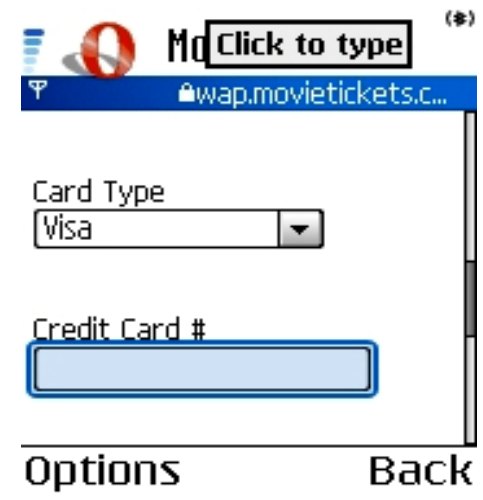

Figure 4: Payment method at movietichets.

\section{EVALUATION RESULTS}

Quality evaluation of m-commerce systems attributes provides a quantitative representation of ecommerce systems' quality. Table 1 provides the evaluation results for the m-commerce attributes presented in section 2. It presents the values of function relevance (r) for each attribute. These values are the average values of all evaluators approximated in monad.

Based on the evaluation results, the quality of mcommerce systems can be modelled in external quality characteristics and attributes. Providing a value for each attribute, an ordered list for each external quality characteristic is provided.

These values provide a first impression of end users preferences and perquisites about $\mathrm{m}$-commerce systems' attributes. 
Table 1: Evaluation results for m-commerce attributes.

\begin{tabular}{|c|c|c|c|c|}
\hline \multirow[t]{2}{*}{ M-commerce attributes } & \multicolumn{4}{|c|}{$\begin{array}{c}\text { Quality } \\
\text { characteristics }\end{array}$} \\
\hline & $\mathbf{F}$ & $\mathbf{U}$ & $\mathbf{E}$ & $\mathbf{R}$ \\
\hline \multicolumn{5}{|l|}{ Presentation } \\
\hline Product's description & 3 & 5 & 3 & 3 \\
\hline Still images & 3 & 5 & 3 & 1 \\
\hline Text & 4 & 5 & 3 & 2 \\
\hline Colors & 3 & 5 & 4 & 2 \\
\hline Graphics & 4 & 5 & 3 & 2 \\
\hline Clarity & 3 & 5 & 4 & 2 \\
\hline $\begin{array}{l}\text { Central meaning of } \\
\text { content }\end{array}$ & 3 & 5 & 4 & 1 \\
\hline Text inputting & 4 & 5 & 4 & 1 \\
\hline Thematic consistency & 2 & 5 & 4 & 2 \\
\hline Provide defaults & 3 & 5 & 4 & 2 \\
\hline \multicolumn{5}{|l|}{ Navigation } \\
\hline Navigation mechanism & 4 & 4 & 4 & 3 \\
\hline Uploading Time & 3 & 3 & 5 & 4 \\
\hline Access keys & 4 & 5 & 4 & 2 \\
\hline Use of Links & 4 & 4 & 3 & 3 \\
\hline Help & 5 & 5 & 3 & 3 \\
\hline Feedback & 3 & 5 & 4 & 3 \\
\hline Undo functions & 5 & 3 & 3 & 5 \\
\hline User oriented hierarchy & 2 & 5 & 4 & 3 \\
\hline Redirection & 5 & 3 & 4 & 3 \\
\hline navigation bar (minimum) & 5 & 5 & 3 & 1 \\
\hline Scrolling & 3 & 5 & 4 & 2 \\
\hline Search response time & 2 & 4 & 5 & 4 \\
\hline Search results processing & 3 & 4 & 5 & 3 \\
\hline \multicolumn{5}{|l|}{ Purchasing } \\
\hline Shopping cart-Metaphor & 4 & 5 & 4 & 2 \\
\hline Security mechanism & 3 & 2 & 4 & 5 \\
\hline Pricing Mechanism & 3 & 4 & 3 & 3 \\
\hline $\begin{array}{l}\text { Alternative payment } \\
\text { methods }\end{array}$ & 4 & 4 & 3 & 4 \\
\hline Authentication & 5 & 2 & 3 & 5 \\
\hline Personalization & 4 & 5 & 4 & 2 \\
\hline Localization & 4 & 5 & 3 & 1 \\
\hline $\begin{array}{l}\text { Transaction recourses } \\
\text { behavior }\end{array}$ & 3 & 3 & 5 & 4 \\
\hline Notification services & 3 & 5 & 3 & 4 \\
\hline Error recovery & 3 & 3 & 3 & 5 \\
\hline Errors tolerance & 4 & 3 & 4 & 4 \\
\hline Stability & 4 & 3 & 3 & 5 \\
\hline
\end{tabular}

The categorization of these attributes provides important feedback for m-commerce systems' assessment which is in an initial stage. By evaluating the attributes that an m-commerce system provides to the end user we also offer an end user perception of quality. End user's experience is a critical determinate of success in mobile web applications. If end users, who are also the customers, cannot find what they are searching for, they will not buy it; a site that buries key information impairs business decision making. Poorly designed interfaces increase user errors, which can be costly. A user-centered evaluation approach supports all the tasks users need to accomplish using different $\mathrm{m}$-commerce systems' attributes. The above evaluation process provides measurement results which can be also be defined as metrics for a quantitative representation of $\mathrm{m}$ commerce systems' quality.

In order to evaluate m-commerce systems features a new metric that summarizes the relevance of each attribute is introduced. The metric Mobile Attributes Weight $(M A W)$ provides an evaluation weight with respect to the four quality characteristics and is calculated by formula 2 ,

$$
M A W=\text { normalized } \sum_{i=1}^{4} r_{i j} \in[0,1]
$$

where $r_{i j}$ is the relevance for every listed $\mathrm{m}$ commerce system attribute. The value for $M A W$ provides a numerical value for every $\mathrm{m}$-commerce system attribute and an ordered list about end user preference based on external quality characteristics. The values for $M A W$ need to be further specified, probably with experience testing in future work and the use of different end users' groups.

The metric MAW actually represents attributes importance for the end-user and as such it can be used at the development phase in order to define end user preferences.

The evaluation process also provided interesting results about the quality characteristics. In an up and down processing of the values for rij, the $\mathrm{WF}=0,24$, $\mathrm{WU}=0,30, \mathrm{WE}=0,26, \mathrm{WR}=0,20$ values have been defined as the normalized average values for each quality characteristic. From these values we conclude that m-commerce end users give great emphasis to Usability and Efficiency issues and somewhat lesser on Functionality and Reliability. These values differ from e-commerce systems where Usability and Functionality have equally great importance (Stefani, 2004). In e-commerce systems the end users expects different and usable functions/services, but in m-commerce systems the end user desires the basic functions with great efficiency when it comes to time and resource behaviour. 


\section{CONCLUSION AND FUTURE WORK}

In this paper, we presented a quality evaluation for selected attributes of m-commerce systems and particularly B2C m-commerce systems. This evaluation provides an extendable framework useful for mobile system developers. We believe that this is a step towards more effective measurement of $\mathrm{m}$ commerce systems' quality. We acknowledge that our attributes do not constitute a complete set and may not cover every aspect of m-commerce systems. The above evaluation results provide an initial research for m-commerce systems' quality.

A metric MAW has also been introduced which measures the value of relevance for each $\mathrm{m}$ commerce system attribute. The theoretical framework for this metric is also presented. The validity of the presented measures should further examine with different user groups in alternative evaluation cases and it is included in future work. It should be mentioned that the values presented are not strictly defined as numerical results but present the correlation among m-commerce systems attributes and external quality characteristics.

Future work includes the development of methods enabling the selection of the most appropriate set of metrics for each evaluation process. We also suggest the creation of an open knowledge base of web-based m-commerce systems' quality factors, criteria, and metrics according to end users' needs.

\section{REFERENCES}

Blekas, A., Garofalakis, J., and Stefanis, V., Use of RSS feeds for Content Adaptation in Mobile Web Browsing, International Cross-Disciplinary Workshop on Web Accessibility, WWW2006, pp. $79-85$.

Clarke, I., Emerging value propositions for m-commerce, Journal of Business Strategies 18 (2) (2001) 133- 148.

Cote, M., Suryn, W., Laporte, C., \& Martin, R. (2005) The Evolution Path for Industrial Software Quality Evaluation Methods Applying ISO/IEC 9126:2001 Quality Model: Example of MITRE's SQAE Method. Software Quality Journal, 13(1), 17-30.

Coursaris, C., Hassanein, K., Understanding m-commerce, Quarterly Journal of Electronic Commerce 3 (3) (2002) 247-271.

ISO/IEC 9126 (2001). Software Product Evaluation Quality Characteristics and Guidelines for the User. Geneva: International Organization for Standardization.
Kwon, O.B., Sadeh, N., Applying case-based reasoning and multi-agent intelligent system to context-aware comparative shopping, Decision Support Systems 37 (2) (2004) 199-213.

Losavio, F., Chirinos, L., Matteo, A., Levy, N., \& Ramdane, A. (2004). ISO quality standards for measuring architectures. The Journal of Systems and Software, 72, 209-223.

Malloy, A., Varshney, U., Snow, A., (2002). Supporting Mobile Commerce Applications Using Dependable Wireless Networks, Mobile Networks and Applications, 7, 225-234,

Mobile Web Best Practices 1.0, W3C Proposed Recommendation. http://www.w3.org/TR/mobile-bp/

Ngai, E.W.T., Gunasekaran, A., (2007). A review for mobile commerce research and applications, Decision Support Systems, 43, 3-15

Nielsen, J., Molich, R., (1990). Heuristic Evaluation Of Users Interfaces, CHI90, pp. 249 - 256

Samaras, G., Mobile commerce: vision and challenges (location and itsmanagement), Applications and the Internet, 2002. (SAINT 2002). Proceedings. 2002 Symposium on, pp. 43-44,

Stefani, A., Stavrinoudis, D., Xenos, M., 2004. Experimental Based Tool Calibration used for Assessing the Quality of E-Commerce Systems. In the IEEE International Conference on E-Business and Telecommunication, Networks, Portugal, ICETE 2004, pp. 26-32.

Stefani, A., Stavrinoudis, D., Xenos, M., 2005.,. In depth analysis of selected topics related to the quality assessment of e-commerce systems. In the International Conference on E-Business and Telecommunication, Networks, Reading, UK, ICETE 2005, pp.122 -128. 